\section{LA ENSEÑANZA SECUNDARIA EN MADRID: ESTUDIO BIBLIOGRÁFICO}

\author{
Miryam Carreño Rivero \\ Sara Ramos Zamora \\ Departamento de Teoría e Historia de la Educación \\ Universidad Complutense de Madrid. Facultad de Educación \\ Calle Rector Royo Villanova s.n. 28040 Madrid
}

\section{SECONDARY EDUCATION IN MADRID: BIBLIOGRAPHIC REVIEW}

ABSTRACT: This paper analyses the historiography of the Secondary Education in the Community of Madrid. The study refers to the contemporary period (nineteenth and twentieth centuries) and focuses especially on the works of historiography published during the last decades.

KEY WORDS: Secondary Education; historiography; Madrid; contemporary period.

\section{INTRODUCCIÓN}

La configuración de la enseñanza secundaria es de fecha relativamente reciente, de ahí que la historia de este nivel de enseñanza sea no sólo un tema nuevo en la historiografía educativa española, sino, también, de producción escasa.

En este artículo analizaremos la historiografía relativa a la educación secundaria en Madrid, limitándonos a la enseñanza pública. El concepto de enseñanza o instrucción pública ha ido variando con el tiempo y, por lo tanto, no siempre ha tenido un significado unívoco'. Aqui entenderemos por enseñanza pública aquella enseñanza secular, sostenida en todo o en parte por la Administración Pública, ya sea ésta local, regional o central $y$, en cualquier caso, teniendo dicha Administración la titularidad del servicio. Debemos decir, sin embargo, que al realizar esta indagación historiográfica nos hemos encontrado con casos de difícil delimitación en este sentido, sobre todo porque no siempre está claro a qué entidad corresponde la titularidad del servicio educativo.

La expresión "enseñanza secundaria" que aquí empleamos es actual y responde a la nomenclatura utilizada por or-
RESUMEN: En este trabajo se analiza la historiografía sobre la educación secundaria en la Comunidad de Madrid. El análisis se refiere a la época contemporánea (siglos XIX y XX) y se tiene especialmente en cuenta las obras de historiografía publicadas en las últimas décadas.

PALABRAS CLAVE: Enseñanza secundaria; historiografía; Madrid; época contemporánea.

ganismos internacionales como la UNESCO, para designar el tramo de las enseñanzas que se sitúan posteriormente a la enseñanza primaria. Por enseñanza secundaria hoy se entiende no sólo la enseñanza académica tradicional, el bachillerato, sino, también, la enseñanza profesional. En la actualidad, pues, este nivel tiene estructura, caracteristicas y finalidades propias². Éstas, han venido evolucionando a lo largo del tiempo de forma tal que no siempre podemos hablar de enseñanza secundaria con propiedad. La sustantividad que hoy tiene este nivel se ha forjado lentamente y en estrecha vinculación con el contexto económico e ideológico. Al ser este grado de enseñanza una creación nueva, vinculada a la conformación de los sistemas escolares nacionales en el siglo XIX, difícilmente podría escapar a las marchas y contramarchas de lo que, por desconocido, se forja entre el ensayo y el error $y$, sobre todo, porque el desacuerdo con respecto a su finalidad ha sido una constante a lo largo de la historia de la educación.

Las transformaciones de la estructura social y los avatares del desarrollo económico, propios del siglo XIX español, le darán a la enseñanza secundaria un carácter de provisionalidad que se manifiesta claramente en las continuas reformas ocurridas a lo largo de este siglo ${ }^{3}$. 


\section{EN EL ANTIGUO RÉGIMEN: UN TIPO DE ENSEÑANZA SITUADA ENTRE LAS PRIMERAS LETRAS Y LAS FACULTADES MAYORES}

Como deciamos, este nivel de enseñanza no existió hasta la conformación de los sistemas escolares nacionales en el siglo XIX. Sin embargo, podemos rastrear, en el pasado anterior, un tipo de enseñanza situada entre las primeras letras y las Facultades mayores que consistía en conocimientos de latín, filosofía y humanidades, cuyo objetivo fundamental, a veces único, era preparar a los alumnos para ingresar en dichas Facultades mayores. Una gran variedad de estudios e instituciones públicas o privadas se encuentran en esta situación. Así, las escuelas de gramática, los estudios de latinidad, las enseñanzas impartidas en colegios no universitarios, en seminarios eclesiásticos o nobiliarios, colegios de humanidades, etc. ${ }^{4}$. Esta enseñanza, casi siempre "media" por su ubicación entre las primeras letras y la universidad era, justamente por ser media o intermedia, propedéutica para la enseñanza universitaria. El carácter de enseñanza mediadora, propedéutica, permanecerá en la mentalidad colectiva prácticamente hasta nuestros días.

Son ésas las instituciones más representativas del Antiguo Régimen que, como él, tardarán mucho en desaparecer. La Villa de Madrid cuenta con una de estas escuelas, la denominada Estudio de la Villa. Es la más antigua de las instituciones civiles, hasta ahora conocidas, dependiente del municipio de esta ciudad, ya que el primer testimonio con que se cuenta sobre el Estudio es la provisión de Alfonso XI fechada el 7 de diciembre de 1346. Por ella se autorizaba a la Villa de Madrid a que estableciese una escuela de Gramática y se retribuyese adecuadamente a sus profesores ${ }^{5}$. Es, por lo tanto, un caso muy antiguo de municipalización de la educación ${ }^{6}$. José M. Bernáldez Montalvo (1989) realiza la historia del Estudio de la Villa en el que destaca la evolución administrativa desde una municipalización progresiva que alcanza su apogeo en 1515, y que, desde entonces, evoluciona según una desmunicipalización gradual no ajena a los intereses de los sectores religiosos, que culminará en la desaparición de este servicio educativo. Un apéndice con tablas cronológicas de gramáticos y salarios, completan el libro. Referencia a esta escuela municipal madrileña encontramos, también, en la obra de J. Simón Díaz (1952) sobre el Colegio Imperial de Madrid7, que amplía en una edición posterior de la misma obra (Simón Díaz, J., 1992).
En el siglo XVIII y durante la primera mitad del XIX, estas instituciones encargadas de los estudios preparatorios para la universidad, enseñanzas nucleadas todavía en la gramática latina, proliferaron en todo el reino ${ }^{8}$. Una burguesía cuantitativamente en expansión reclamaba estos estudios para dar a sus hijos una educación diferenciadora: el adorno que les concediera el sello distintivo de clase. En consecuencia no tenían finalidad práctica alguna. La docencia en este nivel estaba a cargo de las órdenes religiosas, sobre todo de los jesuitas, y de preceptores laicos o dómines generalmente mal preparados y que ejercian este trabajo sólo como un medio de vida, aunque las más de las veces, muy corto ${ }^{9}$. Cuando es expulsada la Compañía de Jesús, el gobierno de Carlos III intenta una planificación de estas enseñanzas en toda la nación, excluyendo a los religiosos de esta actividad docente. Las cátedras se obtendrían por oposición, lo que, teóricamente, garantizaba la calidad de la educación. Es uno de los primeros pasos dados hacia la secularización de la enseñanza.

Era notoria la preocupación de los círculos ilustrados del país por crear nuevos establecimientos de enseñanza en los que predominara el espíritu científico propio de la llustración. Una relación de las instituciones más características de este período, en el ámbito madrileño, ha sido realizada por A. Aparisi Mocholi (1978).

En este contexto de reformas, seguidamente a la expulsión de la Compañía de Jesús, hay que situar la creación de los Reales Estudios de San Isidro. Esta institución madrileña nace de la reorganización de aquélla de los jesuitas no sólo con nuevo nombre sino con un nuevo titular encargado de solventar los servicios docentes y la administración: el Gobierno. El profesor J. Simón Díaz, en su ya citada obra (Simón Díaz, 1952), dedica el tomo segundo a la historia de los Reales Estudios de San Isidro (Simón Díaz, 1959), y en la última edición de la misma obra (Simón Díaz, 1992) los capítulos XXI a XXX. Relaciona aquí los avatares de esta casa de estudios desde su inauguración oficial, el 21 de octubre de 1771, sus supresiones y restablecimientos, hasta que su azarosa vida alcanza el año 1845. Anota, asimismo, algunos aspectos de la vida docente, como las cátedras, el profesorado, los alumnos más destacados, la biblioteca, etc. (Simón Díaz, 1973). Del mismo autor contamos con una historia de la cátedra de hebreo (Simón Díaz, 1948) que funcionó en esta institución desde que fuera implantada por decreto de 19 de enero de 1770. Especial- 
mente interesante, con relación a una futura historia del currículo, es la exposición del programa de la asignatura que realiza el autor en este trabajo.

\section{Hacia la definición de un NUEVo MOdelo}

Los intentos oficiales de reforma del disperso conjunto de estas enseñanzas "medias" no se concretaron hasta bien entrado el siglo XIX en que comienza a definirse ideológicamente este nivel en función de las necesidades de la burguesía -moderada o progresista- que accede al poder.

En cuanto a la procedencia de lo que hoy entendemos por enseñanza secundaria, si bien en el Informe Quintana de 9 de septiembre de 1813 se proponía la organización de una "segunda enseñanza", nosotros situaremos su nacimiento en el Reglamento General de Instrucción publica de 1821. Mediante este reglamento se articuló por primera vez el sistema escolar español en tres grados, siendo el intermedio el que recibiría la denominación de segunda enseñanza, al que se dedicaba el Título III. Con este texto legal se daba al país, en palabras del profesor M. Puelles Benítez, "la primera estructuración moderna de la educación, de acuerdo con los principios liberales triunfantes"10.

A partir de entonces, y hasta nuestros dias, este nivel de enseñanza irá perfilando su estructura y sus fines en estrecho nexo con el entorno económico e ideológico. Los planes y proyectos tanto de organización como de reforma de esta enseñanza nos dan pautas acerca de la percepción que de ella tenían las minorías dominantes que legislaron sobre esta cuestión. Asimismo estos documentos dan testimonio tanto de la evolución conceptual como de los fines que se le han adjudicado a lo largo del tiempo.

De tal forma que en el anteriormente citado Reglamento de 1821, en el artículo 21, se establece que la segunda enseñanza "comprende aquellos conocimientos que al mismo tiempo que sirven de preparación para dedicarse después a otros estudios más profundos, constituyen la civi1ización general de la Nación"11. Nos encontramos, pues, con la novedad de la organización de una segunda enseñanza que se impartiría en las "universidades de provincia", y con un concepto que se deriva de los fines establecidos en el artículo que hemos citado. De él puede inferirse que, para el primer liberalismo, la segunda enseñanza no era sólo una enseñanza media o propedéutica exclusivamente, sino que podría aprovechar a todos. En tanto se la considera una educación necesaria para "la civilización general de una Nación", bien podriamos juzgar que el Reglamento le da a este nivel de enseñanza un carácter terminal, además del propedéutico que queda claramente expresado.

Pero los avatares políticos, la vuelta de Femado VII y la caída del gobierno constitucional, trajeron entre otras consecuencias en materia educativa, la paralización del proyecto emanado del Reglamento de Instrucción Pública. Nunca se llegó a establecer un plan que lo desarrollara. A la muerte de Fernando VII, como dice el profesor Artola, "la Corona renuncia, tras un cuarto de siglo de luchas, a mantener el régimen absoluto, y acepta la ampliación del sistema político en beneficio de la burguesía"12. Es en este contexto, estimulador de la acción de la burguesía tanto en lo político como en lo económico, que debemos situar el resurgir, luego de un largo período de inactividad, de la acción legislativa referida a la enseñanza secundaria.

De cómo el concepto de enseñanza secundaria encaja en el contexto político antes referido, da fe el Plan General de Instrucción Publica, aprobado en 1836, conocido como plan del Duque de Rivas. Aunque nunca llegó a tener vigencia, nos deja un inestimable testimonio de la percepción que la burguesía en el poder tenía de esta etapa de la educación. En su artículo 25 dice: "La instrucción secundaria comprende aquellos estudios a que no alcanza la primaria superior, pero que son necesarios para completar la educación general de las clases acomodadas y seguir con fruto las facultades mayores y escuelas especiales"13. Es clara la función que en este plan se le adjudica a la "instrucción secundaria", como allí se la denomina: seguir con fruto las facultades mayores y especiales. Función, por lo tanto, propedéutica para continuar estudios universitarios que sólo favorecía a aquellos sectores minoritarios con capacidad material para abordar tales estudios. Esta situación también fue denunciada por Pablo Montesino poco tiempo antes al afirmar: "La parte más acomodada de la clase media y toda la clase superior necesitan y desean naturalmente mayor instrucción, y éstos son los que por punto general reciben o deben recibir la segunda enseñanza"14. Se define, pues, en el plan del Duque de Rivas, el carácter elitista que la enseñanza secundaria mantendrá hasta nuestra contemporaneidad. Fue considerada como 
propia de la nueva clase política, consecuentemente se convirtió en instrumento de reproducción de dicha clase y, por lo tanto, de perpetuación del poder político burgués.

El interés por la enseñanza secundaria cobra nuevo tono en el contexto ideológico del moderantismo cuya máxima expresión fue la Constitución de 1845. El moderantismo tenía, entre sus instrumentos de poder político, el sufragio censitario que reservaba la plenitud de los derechos de representación a quienes acreditaran una determinada cuota contributiva. Sin embargo, se reconocía una ventaja a la "inteligencia", ya que se rebajaba dicha cuota a los que poseyeran títulos académicos o profesionales. Como dice el profesor Palacio Atard, "la ecuación doctrinaria, como es bien sabido, se establece así: riqueza + inteligencia = poder"15. Es lo que se ha dado en Ilamar "la soberanía de la inteligencia", pero ésta, dice Puelles Benítez, "pugnaba con el viejo sueño de la instrucción pública universal"16.

En este marco de ideas se aprueba el Plan General de Estudios de 17 de septiembre de 1845, conocido como plan Pidal, que da paso a una nueva etapa en el tema que aquí nos ocupa. Según el profesor A. Viñao, es el momento en que "la nueva enseñanza secundaria va a consolidarse definitivamente con sus rasgos tradicionales, que perdurarán hasta fecha muy reciente, en estos años centrales del siglo $X I X$, en un proceso similar, con muy ligeras variaciones, al que había iniciado la Europa más avanzada"17.

El nuevo plan no cambió el concepto de segunda enseñanza que habíamos visto en el anterior. Su carácter elitista queda expresado en el preámbulo donde se la presenta como "aquella que es propia especialmente de las clases medias"18. Tal concepción que, como ya hemos señalado, responde al contexto económico, político e ideológico, fue claramente expresada por Gil de Zárate en una obra publicada posteriormente.

Después de la primaria -dice-, la segunda enseñanza es la parte más importante de la instrucción pública. Si prescinde de las masas populares, se dirige a las clases altas o medias, esto es, a las más activas y emprendedoras, a las que legislan y gobiernan, a las que escriben, inventan, dirigen y dan impulso a la sociedad, conduciéndola por las diferentes vías de la civilización; en suma, a las que son el alma de las naciones, conmueven los pueblos y causan su felicidad o desgracia. La segunda enseñanza es la que procura a estas clases el desarrollo intelectual necesario para alcanzar tan elevados fines; su trascendencia es por lo tanto inmensa, si se la considera desde el punto de vista social y humanitario (Gil de Zárate, 1845, 1).

El plan Pidal define la segunda enseñanza como "continuación de la instrucción primaria" -art. 2. ${ }^{\circ}$ - y la divide en "elemental" y "de ampliación". En el marco de este plan se crearon los centros de enseñanza para este nivel, que se denominaron "institutos" Éstos vendrán a desplazar definitivamente a los colegios de humanidades del Antiguo Régimen e incluso a las universidades de provincia. Sin embargo, aún no se llevó a cabo una separación entre los estudios secundarios y universitarios, pero se dotó a los institutos de un carácter propio que marcaría el inicio de su futura separación de las universidades. Posteriormente se aprobaron otras reformas, algunas de las cuales estimularon esa separación, pero ésta no se concretará hasta la promulgación de la primera Ley de Instrucción Pública de 1857 o Ley Moyano. Las repercusiones de esta Ley en Madrid han sido analizadas por Aparisi Mocholi (1981).

En el marco legislativo del Plan General de Estudios de 1845 se crearon los primeros institutos en Madrid, el San Isidro y el de Noviciado, posteriormente denominado Cardenal Cisneros. La profesora A. del Valle, en su historia de la Universidad Central, dedica un apartado a este primer momento en que, como dijimos, los institutos no se han separado aún de la universidad; en su texto analiza la segunda enseñanza en el distrito de dicha Universidad (Valle López, 1990).

La investigación de A. Navarro Jurado (1991) sobre el instituto San Isidro perfila la vida de esta institución madrileña, pionera en la enseñanza secundaria, desde sus orígenes hasta 1936. El tratamiento de diferentes aspectos de este centro de estudios, tanto materiales como pedagógicos, permite el acercamiento a la vida y desarrollo de una institución que, por su antigüedad y ubicación en la capital del Reino, bien pudo ser modelo para posteriores creaciones. Especialmente interesante para el conocimiento, no ya de este instituto, sino de la evolución de la enseñanza secundaria en general, son las referencias que el autor realiza sobre las revistas editadas en el San Isidro: La Segunda Enseñanza, Revista de Segunda Enseñanza y El Instituto. En un reciente trabajo, que se recoge en este mismo nú- 


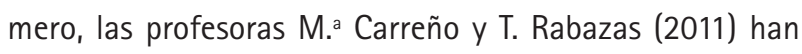
realizado un análisis de dichas revistas.

En su ya citada obra sobre el Colegio Imperial, el profesor J. Simón Díaz realiza, en la séptima parte de la misma, una historia del San Isidro como instituto de segunda enseñanza desde 1845 hasta 1936 (Simón Díaz, J. 1952), $y_{1}$ con datos ampliados, en la edición posterior (Simón Díaz, J.1992). Las referencias realizadas por el autor a la organización interna, a los directores más destacados, a las cátedras, a los gabinetes de física y química, al material científico, a las matrículas y a los estudiantes, así como a los actos públicos más notorios, nos perfilan la vida y funcionamiento de esta institución. Todos estos aspectos constituyen el argumento central de otras aportaciones de este mismo autor, dedicadas en exclusividad al instituto San Isidro (Simón Díaz, 1972a, 1972b).

Además de los trabajos citados anteriormente que muestran una historia global del San Isidro, contamos con otros que hacen referencia a aspectos concretos, como el de M. Santisteban (1875), catedrático del instituto, que aborda la historia de los gabinetes de Física y Química. La descripción monográfica y cronológicamente ordenada de los fondos de dichos gabinetes, lleva al autor a establecer períodos de auge y decadencia de estas disciplinas en España; unos datos que, indudablemente, podrían ser de utilidad en la elaboración de una historia del currículo. Por su parte, A. Miguel Alonso $(1987,1992)$ ha realizado distintas investigaciones sobre la biblioteca y sus fondos. La autora concreta su trabajo en la indagación de la figura y obra de Oliver Lepigont y en su pensamiento sobre los temas fundamentales de la biblioteconomía. Con mayor nivel de profundización esta misma autora realiza un estudio sobre la historia de la biblioteca del instituto San Isidro, desde que toma la denominación de biblioteca pública de San Isidro, según R.D. de 19 de enero de 1770, aunque con antecedentes mucho más lejanos, hasta su integración en la Universidad Central de Madrid (Miguel Alonso, 1996).

Informaciones parciales pero que nos pueden permitir conocer la vida de una institución son las memorias que éstas elaboran, a veces, de precepto. En algunos casos llegan a publicarse como pequeños libros en los que la memoria suele acompañarse de una reseña histórica de la institución. En el caso del instituto que aquí nos ocupa (cuyas Memorias se publicaron entre 1858 y 1923) ${ }^{19}$ contamos con algunas, como la de 1859, en la que se recogen los objetivos trazados para los cursos siguientes. Es de destacar que, entre esos objetivos, figura la adquisición de una completa colección de las nuevas pesas y medidas, "mejora tanto más indispensable cuanto que ha de ser obligatorio el sistema en tiempo muy próximo" (instituto San Isidro, $1859,13)$. Inquietud temprana por un tema que seguiría preocupando a las autoridades educativas por mucho tiempo; el nuevo sistema de medición necesitaría el resto del siglo y algo más para imponerse en todos los sectores sociales ${ }^{20}$. Interesa, también, el apéndice con cuadros de alumnos matriculados en las dos modalidades existentes entonces -estudios generales y de aplicación-, así como de asignaturas, profesores que las impartían, clases y distribución del tiempo escolar.

Sobre la vida interna del San Isidro existe un trabajo de E. Ezquerra Abadia (1984). Después de realizar una breve reseña histórica, el autor se refiere concretamente al período en que cursó sus estudios, 1916-1921, con alusiones a lo que ha podido averiguar de los años inmediatos anteriores y posteriores. Referencias al edificio y a su popular entorno, a los profesores, al tono tradicional de las clases, a los estudiantes, casi todos procedentes de la clase media, ya que eran pocos "en quienes se percibiera un origen más popular" (Ezquerra Abadía, 1984, 20), nos acercan a la vida cotidiana de la institución madrileña. También José Gavira (1973) en su diario de estudiante recuerda los sucesos que más le llamaron la atención del curso 1920-1921. Caracteriza agudamente a profesores, alumnos y bedeles en un relato de la vida y modos del instituto.

Sobre el periodo de la guerra civil e inmediata posguerra ha escrito M. L. Carballo Dávila (1978). Además de exponer una breve nota histórica, el autor hace hincapié en los años de la guerra civil, ya que analiza las consecuencias que la guerra trajo tanto para el profesorado como para el alumnado del San Isidro. Se refiere, también, a las nuevas disposiciones legales surgidas al finalizar el conflicto. Sobre el mismo tema, informa una memoria sobre la vida de esta institución desde 1939 a 1941 (instituto San Isidro, hacia 1941).

El otro instituto creado en Madrid en el mismo contexto legal -el plan Pidal- fue, como deciamos, el Cardenal Cisneros. Sobre su dilatada historia contamos con algunas publicaciones breves que, sin embargo, nos ponen en con- 
tacto con los acontecimientos más destacados de esta institución, aunque sin lograr conformar una historia general (instituto Cardenal Cisneros, 1879, 1880a, 1880b) ${ }^{21}$. Dichas publicaciones dan cuenta de algunas de las actividades de este centro, así como de los planteamientos respecto a los fines y objetivos que orientaban la tarea docente. Una reseña de la institución referida a un período más extenso, es la que se realiza en la publicación hecha con motivo de la celebración de su primer centenario (instituto de Bachillerato Cardenal Cisneros, 1946).

Sin embargo, la profesora de este centro Carmen Rodríguez Guerrero $(2005,2006,2009)$ ha dedicado buena parte de su trabajo de investigación a indagar en los orígenes y etapa inicial de este centro. Especialmente significativa es su última obra en la que traza la historia del Cardenal Cisneros desde su fundación en 1845 hasta el año 1877, trabajo que nos ofrece un conocimiento más acabado de este instituto histórico del que teníamos hasta ahora. En él ofrece un profundo recorrido por un centro educativo de especial importancia en la historia de la educación española del siglo XIX, ubicado en el corazón de la capital del Estado, junto a la Universidad Central. Con abundante material de archivo, la profesora Rodríguez Guerrero muestra como ese instituto se convirtió en un laboratorio de experimentación pedagógica de las distintas sensibilidades educativas que se fueron sucediendo en él en las décadas centrales del siglo XIX, particularmente de las progresistas durante el Sexenio democrático (1868-1874).

El liberalismo democrático, como nuevo sustento ideológico en lo político, traería cambios en la concepción de la enseñanza secundaria. En el preámbulo del citado decreto de 25 de octubre de 1868 que da nueva organización a la segunda enseñanza, se dice que es "la ampliación de la instrucción primera, es la educación necesaria a los ciudadanos que viven en una época de ilustración y de cultura, es el conjunto de conocimientos que debe poseer el hombre que no quiera vivir aislado y fuera de una sociedad en que los principios y las aplicaciones de la ciencia intervienen de un modo importante hasta en los menores actos de la vida pública y doméstica" (MEC, 1979, 340341). Como se puede apreciar existe una gran similitud con el concepto de segunda enseñanza defendido por el primer liberalismo y que analizábamos al comienzo de este trabajo. Sin embargo, los objetivos que se desprenden de él no se concretaron en la práctica. Aunque se intentó una nueva ordenación de este nivel de enseñanza más allá de la pura preparación para la universidad, el latín y las humanidades clásicas siguieron conformando el contenido fundamental, en cambio los aspectos profesional y científico eran escasos.

Muchos fueron los planes que reformaron o simplemente pretendieron reformar la enseñanza secundaria en cuanto a organización, contenidos programáticos, finalidad, profesorado. En varias obras, o bien generales sobre la evolución de la educación en España, o bien específicas dedicadas a la historia de la educación secundaria, se hace referencia a esta cuestión (Díaz de la Guardia, 1988; Gómez García, 1996, 1998, 2001; Puelles Benítez, 1980; Utande Igualada, 1964; Ruiz Berrio, 1980; 2001; Sanz Díaz, 1985; Viñao Frago, 1982; 1992). Este es un fenómeno presente en la educación secundaria desde sus inicios, en la segunda mitad del siglo XIX y que permanecerá hasta bien entrado nuestro siglo. Cada reforma ha tenido el sello del partido en el poder, manifestándose las diferencias ideológicas de un modo general en el peso que en cada plan se le diera a las asignaturas clásicas y humanísticas o a las científicas. Sin embargo, la extensión de este nivel de enseñanza a nuevos sectores sociales se verificó muy lentamente. La escasa extensión de la enseñanza secundaria viene corroborada por el lento crecimiento de la matrícula; a fines del siglo XIX el número de establecimientos prácticamente no había variado. Este hecho viene a confirmar su carácter elitista. En la realidad, más allá del plano teórico de las declaraciones de principios y de la legislación, seguía conceptualizándose como previa a la universidad y no más. Pero no sólo era una enseñanza elitista sino también discriminatoria. Aunque no había ninguna disposición que prohibiera la matrícula femenina, el acceso de las jóvenes a los institutos en el siglo XIX se veía dificultado no sólo por la mentalidad de la época que desaconsejaba la reunión de los dos sexos en las clases, sino porque la solicitud de matrícula de las jóvenes debía ser objeto de autorizaciones especiales. Un estudio sobre el proceso de incorporación de las mujeres a la enseñanza secundaria oficial en Madrid en el período 1900-1930, fue realizado por N. Araque (2001). La autora analiza el cambio de normativa, la Real Orden de 8 de marzo de 1910, que admitió la matriculación de las alumnas en igualdad de condiciones con los alumnos. Analiza, también, la evolución del alumnado femenino en los institutos de Madrid en el período señalado. 
En el caso de Madrid, durante el siglo XIX existian estos dos institutos, creados por el plan Pidal, el San Isidro y el Cardenal Cisneros. En el primer tercio del siglo XX, debido al crecimiento de la población se produjo un aumento en el número de matrículas en esos institutos, lo que trajo como consecuencia la creación de nuevos institutos.

Muy pobre es la historiografía sobre la enseñanza secundaria madrileña en el presente siglo. Existen algunas publicaciones que, sin embargo, no nos permiten más que visiones parciales $y_{1}$ a veces, descontextualizadas de la evolución de este nivel de enseñanza en el territorio que estudiamos.

Dentro de la tradicional política de separación de sexos, se inserta la creación del instituto femenino Infanta Beatriz. Por R.D. de 14 de noviembre de 1929, durante la dictadura de Primo de Rivera. El ministro Eduardo Callejo de la Cuesta creó la citada institución que tuvo su sede en el número 14 de la calle Zurbano. La profesora N. Araque Hontangas (2001) realiza en estos momentos un estudio sobre la corta vida del Infanta Beatriz, desde la creación hasta su desaparición en la Segunda República, cuya política de coeducación llevó a eliminar este tipo de instituciones ${ }^{22}$. Por Decreto de 29 de agosto de 1931, el instituto Infanta Beatriz se convirtió en el instituto nacional de enseñanza media Cervantes (instituto de Bachillerato Cervantes, 1982, 19-20).

Sobre el instituto Lope de Vega contamos con una publicación realizada con motivo de la celebración del cincuentenario de su fundación-creado por R.D. de 26 de agosto de 1933-. En este trabajo se realiza una reseña histórica del instituto en la que se destaca su carácter de superviviente de los únicos tres institutos que funcionaron durante la guerra civil. La publicación recoge las conferencias que se dieron con motivo de dicha celebración, algunas de ellas de interés historiográfico como "La reforma educativa de la República en 1933", "Historia del instituto" o "Madrid en la época de la creación del instituto Lope de Vega", etc. (instituto Lope de Vega, 1984).

En cuanto al instituto Isabel la Católica, fue creado en el año 1918 como Instituto-Escuela Sección Retiro hasta el año 1936. En la inmediata posguerra, reabre sus puertas bajo la denominación de instituto Isabel la Católica, funcionando como centro femenino hasta el año $1984^{23}$. Sobre esta institución existen algunas publicaciones. Jiménez de
Gregorio se ha ocupado de describir la situación geográfica del instituto en el denominado "cerrillo de San Blas" y de la extracción social del alumnado. Realiza, también, una reseña histórica que reúne sus antecedentes, enraizados en la idea de los institutos-escuelas; la creación del Isabel la Católica, en 1939, como centro que recogió en sus fines y objetivos las ideas educativas del nuevo régimen político; su evolución, curso por curso, relatando las incidencias más notables en cada uno de ellos. Asimismo aparecen referencias a las sucesivas legislaciones y a cómo éstas afectaron a la marcha del instituto (Jiménez de Gregorio, F. 1990). C. Masip y E. Martínez (2008) realizan un estudio sobre el origen e ideario de esta institución, sobre su profesorado y alumnado ilustre, así como sobre el material histórico pedagógico y los laboratorios.

También del período de la posguerra data la creación del instituto Ramiro de Maeztu que se instaló en el edificio del Instituto-Escuela -nos referiremos a él más adelante-y que se conformó como modelo de institución de enseñanza secundaria del nuevo régimen político. Una historia de este centro es abordada por T. Alvira Alvira, profesor del Ramiro desde su creación por Orden Ministerial de 4 de abril de1939. Realiza, el autor, una relación detallada del profesorado, organización, asociaciones ligadas al centro, bibliotecas y de las actividades más destacadas llevadas a cabo por esta institución (Alvira Alvira, T., 1992).

La enseñanza secundaria en este período de posguerra acentuaba su carácter elitista. Este nivel de enseñanza se regirá en la inmediata posguerra por una nueva ley, la de 20 de septiembre de 1938 que "reforma la parte más importante de la Enseñanza Media el Bachillerato Universitario", según se dice en el preámbulo de dicha ley. La importancia que se le dio a la secundaria queda reafirmada cuando, seguidamente, en el mismo texto, se dice que la enseñanza media "es el instrumento más eficaz para, rápidamente influir en la transformación de una sociedad y en la formación intelectual y moral de sus futuras clases directoras" Aunque el bachillerato no será el único tipo de enseñanza media ya que "otras enseñanzas de carácter más práctico y de utilitarismo más inmediato vendrán a recoger otros sectores sociales" 24 . La regulación de estas otras enseñanzas se produciría posteriormente. En cuanto al contenido curricular de este bachillerato hay que destacar, como corresponde a una enseñanza elitista, el predominio de las asignaturas del ámbito humanístico-clásico, 
acompañadas de contenidos católicos y patrióticos, "El catolicismo es la médula de la historia de España" se dice en el mismo texto. El nuevo régimen político necesita, también, de un profesorado afín que no obstaculice la transmisión de los aspectos ideológicos. Un estudio sobre el profesorado de los institutos nacionales ha sido realizado por la profesora N. Araque Hontangas (2008), en el que analiza la clasificación del personal docente de los institutos, el acceso a la función docente, el régimen especial de acceso para los combatientes, etc.

Los institutos, pues, serán, según los principios que se sustentan a través de la citada ley, establecimientos restrictivos y restringidos. La extensión de la enseñanza secundaria se verá dificultada por el acentuado carácter selectivo del nuevo bachillerato. La escasa expansión que se produjo se llevó a cabo en el ámbito de la enseñanza privada. Pero, indudablemente, como señala M. Utande "el mundo iba por otros derroteros tanto en el orden político como en la esfera docente y la realidad se impondría sin remedio"25, lo que demuestra la necesidad de rectificación de esta ley limitativa y elitista. Esa rectificación se producirá a partir de sucesivas legislaciones que fueron enmendando poco a poco las caracteristicas antes mencionadas. Sobre las circunstancias políticas de esta ley, así como sobre los principios fundamentales que de ella derivaban, el plan de estudios que introdujo, la evolución y desgaste que sufrió esta ley hasta 1968 escribe el autor citado antes (Utande Igualada, 1975). Por otra parte, los cambios económicos y sociales -la recuperación económica, el crecimiento demográfico, el aumento del nivel de vida y de las aspiraciones educativas- en las décadas de los años cincuenta y sesenta, produjeron una mayor demanda de este nivel de enseñanza. A ella se respondió desde una infraestructura deficitaria lo que vino a provocar el surgimiento de defectos que persistirian por mucho tiempo, como la masificación, el abandono, la repetición, los altos porcentajes de suspensos, el desfase entre crecimiento de alumnos y profesores, etc. (Fernández Enguita, M., 1987).

El esfuerzo por superar estos problemas culmina con la reestructuración de la enseñanza secundaria con la Ley General de Educación de 1970 que marca un cambio profundo que operará en todos los niveles de la enseñanza, también en la secundaria en la que comienza a apostarse por la enseñanza comprensiva, ensayada desde hacía más de dos décadas en algunos países europeos ${ }^{26}$.
La preocupación por la formación del profesorado de la segunda enseñanza se pone de manifiesto, aunque por parte de una minoria de educadores, desde finales del siglo XIX. Así, en el Congreso Pedagógico de 1892 se presentó a debate la cuestión de la segunda enseñanza, sin duda por influencia de los institucionistas, que ocupó la sección segunda del Congreso. El séptimo tema de discusión de dicha sección, hace referencia a la formación y selección del profesorado de segunda enseñanza. En la sesión del día 15 de octubre de 1892 se aprobó por unanimidad, a modo de recomendación, una proposición que expresaba la conveniencia de crear una escuela especial pedagógica en la que los profesores, después de terminar la carrera, aprendiesen el difícil arte de enseñar ${ }^{27}$. Un análisis de los planteamientos sobre la formación del profesorado de secundaria realizada por los profesores de la enseñanza pública en las primeras décadas del siglo XX, ha sido realizado por las profesoras M. Carreño y T. Rabazas (2009). En él se estudian las posiciones que adoptaron los profesores con respecto a este asunto, indagando para ello en la prensa pedagógica de la época. También sobre el mismo tema y en el período que se extiende desde 1936 a 1970, ha investigado el profesor J. A. Lorenzo (2001). Este trabajo está recogido en un libro que comprende el análisis de la política y la legislación del período, así como las teorías acerca de la formación de los profesores de este nivel de enseñanza, las instituciones para su formación y un estudio comparado del caso español con otros países de Europa. Podemos ver la génesis de las corrientes actuales sobre la formación del profesorado en el trabajo del profesor Ruiz Berrio (1993), quien señala que este proceso está vinculado al movimiento pedagógico reformista de la Institución Libre de Enseñanza (ILE).

Como deciamos anteriormente, es escasa la historiografía educativa sobre Madrid, especialmente la referida al siglo XX, por otra parte, reducida a historias parciales, casi siempre de instituciones educativas. La historia de algunos institutos -el San Isidro, el Cardenal Cisneros, el Lope de Vega, según lo señalado en párrafos anteriores- constituye la parte nuclear de la historiografía hoy existente referida a la enseñanza secundaria madrileña. Sin embargo, este estudio histórico de casos particulares que, por otra parte, responde a métodos de investigación superables $y_{\text {, en }}$ parte, superados, tendrá que complementarse con investigaciones orientadas según enfoques globales. Así podre- 
mos construir una historia de la enseñanza secundaria en la Comunidad de Madrid atendiendo a las características distintivas que este contexto le proporcionó. Para ello es necesario establecer nexos entre las instituciones y su entorno económico e ideológico y constatar convergencias o divergencias entre ambos. Se hace necesario investigar sobre los fines y objetivos propuestos para este nivel según se infiera de la legislación, de los planes y programas; indagar sobre los contenidos curriculares (libros de texto, horarios, materiales y recursos, métodos, evaluación, espacios, predominio de determinadas asignaturas sobre otras, etc.), sobre la formación y selección del profesorado, etc. En este sentido se orienta el Programa de Actividades de I+D entre grupos de Investigación de la Comunidad de Madrid dirigido por el profesor Leoncio López-Ocón, que Ileva por título "Ciencia y educación en los institutos madrileños de enseñanza secundaria a través de su patrimonio cultural (1837-1936)" (CEIMES) proyecto concedido en el período de 2008 a 2011.

Queda por realizar, también, una historia que refleje los cambios ocurridos en la secundaria cuando comienza a producirse la popularización del bachillerato, a partir de la segunda mitad del siglo $X X$, las barreras surgidas, bien al amparo de la legislación bien desde el currículo, para preservar el carácter y objetivos propios del bachillerato tradicional, impidiendo así el acceso masivo a la universidad. La historia, asimismo, de los intentos por superar esas barreras, intentos y realizaciones que han llevado desde una segregación temprana a la unificación, al menos en teoría, del primer ciclo secundario, atendiendo a principios de comprensión.

\section{LA RENOVACIÓN PEDAGÓGICA}

Con respecto a la renovación pedagógica, la historia de la educación madrileña cuenta con uno de los más significados ensayos pedagógicos españoles en este sentido; una iniciativa de renovación y modernización de la enseñanza que situó a España al unísono con los otros países europeos y que marcó un hito en la historia de las realizaciones educativas españolas. Nos referimos a la creación del Instituto-Escuela. La historia de esta institución ha sido abordada por Palacios Bañuelos (1988). En esta obra el autor recoge su evolución desde el decreto que lo creó en 1918, contextualizándolo en el cuadro gris de la realidad educativa de la época. Mediante el análisis del decreto, destaca sus aspectos más notables, aquellos que van a caracterizar el proyecto: el porqué del nuevo centro; su planteamiento como ensayo pedagógico para la enseñanza secundaria $y$, en consecuencia, su carácter experimental; la obligación de nuevos métodos y planes de estudio, los objetivos, la organización, el personal docente, las instalaciones, el presupuesto y el control del ensayo por parte del Ministerio. El libro se completa con un apéndice documental.

En un apartado de la ya citada obra de Díaz de La Guardia tenemos, también, referencias al Instituto-Escuela, en él se atiende, fundamentalmente, a su organización y a sus realizaciones (Díaz de la Guardia, E., 1988). De igual modo Buenaventura Delgado (1994) hace alusión en su obra Historia de la educación en España y América, a los institutos de segunda enseñanza, en concreto al InstitutoEscuela de Madrid. El profesor Viñao Frago (2000) aborda el estudio de esta institución como modelo de innovación educativa. Hay que destacar, también, las contribuciones a la historia de esta institución de Merinero Martín (1983) y Elvira Ontañón (1988; 2006; 2007), y de esta última en colaboración con Luis Vázquez de Castro (Ontañón y Luis Vázquez de Castro, 2006).

Reviste especial interés para el estudio y conocimiento del Instituto-Escuela la obra recientemente publicada por E. Martínez Alfaro (2009). La autora analiza el contexto en el que se desarrolló dicha institución al amparo de la Junta para Ampliación de Estudios; sus similitudes y concordancia con los principios pedagógicos europeos más innovadores -haciendo alusión específicamente a los principios que sustentaron el movimiento de renovación pedagógica de la Escuela Nueva-. Estudia detenidamente las sedes del instituto, especialmente la sección del Retiro. Analiza, además, la metodología empleada, el profesorado, la organización administrativa, el alumnado y la práctica pedagógica. Realiza un recorrido por las diferentes etapas por las que pasó la institución hasta el inicio de la guerra civil española. Pasado y presente que entronca con la recogida de testimonios orales de antiguos alumnos y del profesor Manuel de Terán.

El Instituto-Escuela conformó un contexto excelente para elaborar y desarrollar nuevos enfoques educativos y me- 
todológicos, especialmente de las asignaturas de carácter científico, así como para la implantación de un modelo innovador de profesorado mejor preparado y formado ${ }^{28}$. Sobre este aspecto hay que destacar varios trabajos publicados por J. D. López Martínez y M. Bernal Martínez $(2000,1998)$. En este ambiente cultural y científico destaca el trabajo desempeñado por las mujeres científicas de esa época y su contribución a la construcción y consolidación de la enseñanza de las ciencias en España. Es el caso de la obra de M. ${ }^{a}$ A. Delgado Martínez (2009) que se detiene en el estudio de la participación de las mujeres en los foros de actualización científica y pedagógica como en la JAE ${ }^{29}$, y su presencia en los institutos y universidad, entre otros aspectos.
Imprescindible para el conocimiento de este experimento pedagógico es la publicación de la Junta para Ampliación de Estudios (1925) en el que se expresa se expone su carácter de laboratorio pedagógico, sus fines, su función de formación del profesorado y, en general, el espíritu del Instituto-Escuela que "no ha sido ni un cuerpo de dogmas pedagógicos reconocidos por todos, ni una imposición autoritaria de determinadas normas" (Ibidem, p. XIII). Varios capítulos dedicados a enseñanzas y métodos nos ponen en contacto con los programas, contenidos y criterios metodológicos que utilizó esta institución. Un apartado dedicado a los resultados nos ofrece una evaluación de la tarea realizada hasta 1925.

\section{NOTAS}

1 Sobre este tema puede verse Ruiz Berrio (1994, 77-85).

2 En el sistema educativo español actual el término educación secundaria alberga una mayor complejidad. Incluye la educación secundaria obligatoria y la educación secundaria postobligatoria que comprende, a su vez, el Bachillerato, la Formación Profesional de grado medio, las enseñanzas profesionales de artes plásticas y diseño de grado medio y las enseñanzas deportivas de grado medio. Los principios generales, objetivos, pedagógicos, evaluación etc. de este nivel de enseñanza, se establecen en los artículos 22 al 44 de la Ley Orgánica de Educación de 3 de mayo de 2006. BOE, n. ${ }^{106}$, 4-IV-2006.

3 Sobre las reformas de los planes de estudio de la enseñanza secundaria puede verse: Utande Igualada (1964); Puelles Benitez (1980); Negrin Fajardo (1983); Díaz de La Guardia (1988). Una evolución cronológica e ideológica puede verse, entre otros autores, en: Utande Igualada (1982); Viñao Frago (1992).
4 Sobre este tema véase: Aguilar Piñal (1988).

5 Sobre esta provisión puede verse: Documentos del Archivo General de la Villa de Madrid interpretados y coleccionados por Timoteo Domingo Palacio. Tomo 1 (1888). Madrid, Imprenta Municipal.

6 Sobre las iniciativas municipales de educación véase: (Escolano Benito, 1984).

7 Para profundizar más en el estudio de esta institución: (Simón Díaz, 1959).

8 Véase el estudio realizado por (Aguilar Piñal, 1988).

9 Sobre este tema puede verse: (Aguilar Piñal, 1968, 1970).

10 Puelles Benitez, M. $(1980,75)$.

11 El texto completo en: (MEC, 1979).

12 Artola $(1974,174)$.

$13 \operatorname{MEC}(1979,124)$.

14 Montesino, P. (1836): Ligeros apuntes y observaciones sobre la instrucción secundaria o media, y la superior o de universidad, Madrid: Librería de Sojo, pp. 16-17. Citado en Ruiz Berrio $(2001,84)$.

15 Palacio Atard $(1978,229)$.

16 Puelles Benitez, M. $(1980,119)$.

17 Viñao Frago $(1975,13)$. La Revista de Educación, el número 238 (mes
Aceptado: 30 de junio de 2010 
mayo-junio) -en el que aparece el artículo mencionado-, es un monográfico dedicado a la educación secundaria, en el que aparecen distintos estudios sobre este nivel de enseñanza en el panorama español e internacional.

$18 \operatorname{MEC}(1979,192)$.

19 Las memorias del instituto San Isidro se encuentran digitalizadas en la página de la Biblioteca Virtual del Patrimonio Bibliográfico, también en la del programa CEIMES (www. ceimes.es).

20 Sobre este tema puede verse: Carreño (1996).

21 El Fondo histórico de la Biblioteca Regional Joaquín Leguina contiene varios documentos relacionados con la historia, el currículum y las actividades del instituto Cardenal Cisneros.

22 La citada Orden de 14 de noviembre de 1929, crea los dos primeros institutos locales femeninos. El segundo se crea en Barcelona con el nombre de Infanta Cristina. Ambos llevan los nombres de las hijas de Alfonso XIII.

23 Masip Hidalgo y Martínez Alfaro (2008).

$24 \mathrm{El}$ texto completo de la ley puede verse en Utande Igualada (1964, 443-457).

25 Utande Igualada $(1982,30)$.

26 Las publicaciones de Fernández Enguita ofrecen un análisis claro sobre la enseñanza secundaria, específicamente en el contexto de la LGE de 1970. Véase Fernández Enguita (1987, 1992); Levin y Fernández Enguita (1989).

27 Congreso Pedagógico Hispano-Portugués-Americano. Trabajos preparatorios del Congreso. Actas. Resúmenes generales. Madrid, Librería de la Viuda de Hernando, p. 50.
28 Sobre la formación del profesorado de esta institución contamos también con el trabajo de Ramirez Aisa (1994).

29 Junto a otras publicaciones relacionadas con la JAE en su centenario, en 2007 se publica un catálogo en el que aparecen una serie de estudios que de forma colateral dan cuenta de las posibles influencias que las iniciativas innovadoras de la JAE van a tener en el InstitutoEscuela. En tal sentido puede verse la obra de Sánchez Ron; Lafuente; Romero y Sánchez (ed.) (2007).

\section{REFERENCIAS BIBLIOGRÁFICAS}

Aguilar Piñal, F (1988): "Entre la escuela y la universidad: la enseñanza secundaria en el siglo XVIII", Revista de Educación (Número Extraordinario): 225-243.

- (1970): "Noticia bibliográfica de la Real Sociedad Económica Matritense de Amigos del País en el siglo XVIII", Anales del Instituto de Estudios Madrileños, Tomo IV, Madrid, CSIC, pp. 319-350.

- (1968): "La Real Academia Latina Matritense en los planes de la llustración", Anales del instituto de Estudios Madrileños, Tomo III, Madrid, CSIC, pp. 183-217.

Alvira Alvira, T. (1992): El "Ramiro de Maeztu", pedagogía viva, Madrid, Rialp.

Aparisi Mocholi, A. (1978): La enseñanza en Madrid en el siglo XVIII, Madrid, Instituto de Estudios Madrileños del CSIC.

- $\quad$ (1981): La Ley Moyano de 1857 y sus repercusiones en Madrid, Instituto de Estudios Madrileños del CSIC.

Araque Hontangas, N. (2001): "El instituto femenino Infanta Beatriz y la inserción de las mujeres en los institutos de Enseñanza Secundaria de Madrid (1900-1930)", Revista Complutense de Educación, Vol. 12 (2): 753-781.

- (2008): "El profesorado de los Institutos Nacionales de Enseñanza media (1938-1970)", Revista Complutense de Educación, Vol. 19 (2): 427-446.

- (2008): El instituto Femenino de Enseñanza Media "Isabel La Católica", Universidad Complutense de Madrid, tesis inédita.

Artola, M. (1974): Partidos y programas politicos. 1808-1898, Madrid, Aguilar, p. 174.

Bernal Martínez, M. (2002): "Innovación pedagógica y enseñanza de la física y química en el Instituto-Escuela de Madrid", Boletín de la Institución Libre de Enseñanza (47): 63-83.

Bernáldez Montalvo, J. M. (1989): Historia de una institución madrileña: el estudio de la villa (a. 1290-1619): la enseñanza como servicio municipalizado en Madrid (y otras cosas más), Madrid, Ayuntamiento de Madrid.

Carballo Dávila, M. L. (1978): El Instituto de San Isidro de Madrid (1936-1943), Anales del Instituto de Estudios Madrileños, Madrid, T. 15.

Carreño, M. (1996): "Introducción del sistema métrico decimal en el currículo escolar", IX Coloquio Nacional de Historia de la Educación. El Currículo: historia de una mediación social y cultural, Granada: Universidad de Granada, Vol. 1., pp. 71-78.

Carreño Rivero, M. y Rabazas Romero, T. (2009): "Prensa pedagógica y formación del profesorado de enseñanza secundaria en la primera mitad del siglo XX en España", en Genovesi, G. (coord.), La formazione docente tra attualità e storia, Universidad de Ferrara, Ferrara (Italia), pp. 214-230.

Delgado Criado, B. (coord.) (1994): Historia de la educación en España y América, Volumen 3, pp. 785-789. 
Delgado Martínez, M. D. y Delgado, M. ${ }^{a}$ A. (2009): Cientificas y educadoras. Las primeras mujeres en el proceso de construcción de la didáctica de las Ciencias en España, Murcia, Editum, Ediciones de la Universidad de Murcia.

Díaz de La Guardia, E. (1988): Evolución y desarrollo de la enseñanza Media en España de 1875 a 1930, Madrid, CIDE.

- (1984): "Municipalidad y educación. Reflexiones desde la historia y la educación Comparada", Historia de la Educación (3): I35-I50.

Ezquerra Abadía, R. (1984): Recuerdos del Instituto de San Isidro, Madrid, Ayuntamiento de Madrid.

Fernández Enguita, M. (1987): Reforma educativa, desigualdad social e inercia institucional: la enseñanza secundaria en España, Barcelona, Laia.

- $\quad$ (1992): "Las enseñanzas medias en el sistema de la Ley General de Educación", Revista de Educación (Número Extraordinario 1): 73-87.

Gavira Liartín, J. (1973): Diario de un estudiante del Instituto de San Isidro (1920-1921). Con un estudio preliminar de Ramón Ezquerra Abadia, Anales del Instituto de Estudios Madrileños, (T. 9), 521-529.

Gil de Zárate, A. (1885): De la Instrucción Pública en España, Madrid, Imprenta del Colegio de sordomudos, Vol. II.

Gómez García, M. ${ }^{a}$ N. (2001): "La educación secundaria pública: un antes y un después de la Creación del Ministerio de Instrucción Pública y Bellas Artes", en AA.W., Cien años de educación en España, en torno a la Creación del Ministerio de Instrucción Pública y Bellas Artes, Madrid, Fundación BBVA y MECyD (pp. 409-431).

- (1998): "Introducción a la historia de la Educación Secundaria", Historia de la Educación (17): 5-14.
- (1996): Pasado, presente y futuro de la Educación Secundaria en España, Sevilla, Kronos.

Informe (1975): "Informe de la ILE sobre la segunda enseñanza y su reforma", Revista de Educación (238): 110-129.

Iniesta Oncea, A. (1975): "España: Bachillerato 1975", Revista de Educación (238): 15-26.

Instituto de San Isidro (hacia 1941): Resumen de la vida de este Instituto desde el $1 .^{\circ}$ de mayo de 1939, Año de la Victoria, hasta el 31 de diciembre de 1941, Madrid, Instituto de San Isidro, Antiguos Estudios de Madrid.

- (1859): Memoria acerca del estado del Instituto de segunda Enseñanza de San Isidro Madrid, Imprenta de S.M. Ducazcal.

Instituto de Bachillerato Cardenal Cisneros (1946): Instituto de Enseñanza Media Cardenal Cisneros I Centenario (18451945), Madrid (s.n)

Instituto del Cardenal Cisneros (1879): Brevísima reseña de las conferencias académicas celebradas en el Instituto del Cardenal Cisneros durante el curso 1878 a 1879, Madrid, Imprenta y Estereotipia de Aribau y Cía.

- (1880a): Brevísima reseña de las conferencias académicas celebradas en el Instituto del Cardenal Cisneros durante el curso 1879 a 1880, Madrid, Imprenta y Estereotipia de Aribau y Cía.

- (1880b): Breve noticia histórica del Instituto del Cardenal Cisneros: sucinto extracto de la reseña histórica y estadística del establecimiento, Madrid, Imprenta y Estereotipia de Aribau.

Instituto de Bachillerato Cervantes (1982): Miscelánea en su centenario, Madrid, Ministerio de Educación y Ciencia.

Jiménez de Gregorio, F. (1990): El Instituto Isabel la Católica en la cultura madrileña, Madrid, Instituto de Estudios Madrileños.
Junta para Ampliación de Estudios (1925): Un ensayo pedagógico. El Instituto Escuela de segunda enseñanza de Madrid, Madrid, Tipografía de la Revista Archivos.

Levin, H. y Fernández Enguita, M. (1989): "Las reformas comprensivas en Europa y las nuevas formas de desigualdad educativa", Revista de Educación (289): 49-64.

López Martínez, J. D. y Bernal Martínez, J. M. (2000): "¿Una nueva concepción del papel de los contenidos en la enseñanza de las ciencias?: el Instituto-Escuela de Madrid y la enseñanza de los procedimientos en la física y química de secundaria", en Ausejo Martínez, E. y Beltrán, M. ${ }^{a}$ C. (coord.): La enseñanza de las ciencias: una perspectiva histórica, Volumen 2 (pp. 707-724), Zaragoza, Universidad de Zaragoza, Seminario de Historia de la Ciencia y de la Técnica de Aragón.

- (1998): "El Instituto-Escuela de Madrid y el cambio en la concepción del trabajo práctico en la enseñanza de la física y química", en Banet Hernández, de Pro Bueno, A. Investigación e innovación en la enseñanza de las ciencias (pp. 74-84), Volumen 1.

Lorenzo Vicente, J. A. (2001): La formación del profesorado de la enseñanza media en España. (1936-1970), Madrid, Editorial Complutense.

- (1983): "Una experiencia de formación de profesores de segunda enseñanza: La Escuela Normal de Filosofía (1846-1852)", Historia de la Educación (2): 97-104.

Martínez Alfaro, E. (2009): Un laboratorio pedagógico de la JAE. El Instituto-Escuela Sección Retiro de Madrid, Madrid, Biblioteca Nueva/CEIMES.

Masip Hidalgo, C. y Martínez Alfaro, E. (2008): "IES Isabel la Católica de Madrid", Participación Educativa (7): 73-78. 
MEC (1979): Historia de la educación en España, Tomo II. De las Cortes de Cádiz a la revolución de 1868, Madrid, Ministerio de Educación, p. 46.

Merinero Martín, M. a Jesús (1983): "Contemporaneidad del Instituto-Escuela", Norba. Revista de arte, geografía e historia (4): 417-426.

Miguel Alonso, A. (1996): La biblioteca de los Reales Estudios de San Isidro de Madrid (su historia hasta la integración en la Universidad Central), Madrid, Fundación Universitaria Española.

- (1992): La biblioteca de los Reales Estudios de San Isidro, Madrid, Editorial Universidad Complutense de Madrid.

- (1987): La obra de Oliver Legipont y la biblioteca de San Isidro, en Madrid, Madrid, Asociación Española de Archiveros, Bibliotecarios, Museólogos y Documentalistas.

- (1982): "El modelo de la Ley General de Educación y la Evaluación Oficial de sus resultados", Revista de Educación (271): 43-70.

Ministerio de Instrucción Pública y Bellas Artes (1921).

Navarro Jurado, A. (1991): Historia del Instituto de Enseñanza Secundaria San Isidro de Madrid (1845-1936), Tesis Doctoral Inédita.

Negrín Fajardo, 0. (1983): "Algunas caracteristicas de la enseñanza secundaria española decimonónica a través de la legislación", Historia de la educación (2): 275-286.

Ontañón, E. (2007): "El Instituto-Escuela, una experiencia educativa ejemplar", Circunstancia: revista de ciencias sociales del Instituto Universitario de Investigación Ortega y Gasset (14). Ejemplar dedicado a Europa por la vía de la ciencia: La JAE.

- (1988): "El Instituto-Escuela nació hace setenta años", Boletín de la Institución Libre de Enseñanza (6): 126128.
Ontañón, E. y Vázquez de Castro, L. (2006): "El Instituto-Escuela y sus edificios e instalaciones", Boletín de la Institución Libre de Enseñanza (63-64): 279-300.

Palacio Atard, V. (1978): La España del siglo XIX. 1808-1898, Madrid, EspasaCalpe, p. 229.

Palacios Bañuelos, L. (1988): InstitutoEscuela. Historia de una renovación educativa, Madrid, MEC.

Puelles Benítez, M. (1980): Educación e ideología en la España contemporánea, Barcelona, Labor.

Ramírez Aisa, E. (1994): "La formación inicial del profesorado en el InstitutoEscuela", Espacio, tiempo y forma. Serie V, Historia contemporánea (7): 563-584.

Rodríguez Guerrero, C. (2009): El Instituto del Cardenal Cisneros de Madrid (1845-1877), Madrid, Consejo Superior de Investigaciones Científicas.

- (2006): "El Instituto de Segunda Enseñanza del Noviciado de Madrid, laboratorio de ensayo para la renovación de la enseñanza oficial (18681872)", Boletín de la Institución Libre de Enseñanza (61): 41-60.

- (2005): "Historia de las bibliotecas escolares: 160 años de bibliotecas en los Institutos de Educación Secundaria (1845-2005)", Primeras noticias. Revista de Literatura (211): 47-52.

Ruiz Berrio, J. (2001): "Instrucción versus formación, una constante de la enseñanza secundaria", Revista Española de Educación Comparada (7): 77-102.

- $\quad$ (1994): "La escuela pública", en Guereña, J. L.; Ruiz Berrio, J. y Tiana Ferrer, A., Historia de la Educación en la España contemporánea, Madrid, CIDE.

- (1993): "Aportaciones de la ILE a la formación universitaria del profesorado", Revista Complutense de Educación, Vol. 41 (1): 209-232.
- (1980): "Estudio histórico de las instituciones para la formación de profesores", en La investigación pedagógica y la formación de profesores, Madrid, Sociedad Española de Pedagogía.

Sánchez Ron, J.; Lafuente, A. Romero, A. y Sánchez, Andrés, L. (ed.) (2007): El laboratorio de España. La Junta para Ampliación de Estudios e Investigaciones Científicas (1907-1939), Madrid, Residencia de Estudiantes y Sociedad Estatal de Conmemoraciones.

Santisteban, M. (1875): Breve historia de los gabinetes de Física y Química del Instituto de San Isidro de Madrid, Madrid, Imprenta de la viuda de Aguado e Hijo.

Sanz Diaz, F. (1985): La Segunda Enseñanza Oficial en el siglo XIX, Madrid, MEC, Breviarios de Educación.

Simón Díaz, J. (1992): Historia del Colegio Imperial de Madrid: (del Estudio de la Villa al Instituto de San Isidro, años 1346-1955), Madrid, Instituto de Estudios Madrileños, 2. ${ }^{\text {a edición }}$ actualizada.

- (1973): "Los Reales Estudios de San Isidro. Nuevas Noticias", AIEHM (IX): 323-340.

- $\quad$ (1972a): El instituto San Isidro (15721972), Madrid: Ayuntamiento.

- (1972b): "El instituto de San Isidro", UM (37): 19-24.

- $\quad$ (1952-1959): Historia del Colegio Imperial de Madrid, tomos I y II, Madrid, Instituto de Estudios Madrileños.

- $\quad$ (1948): "La Cátedra de Hebreo en los Estudios de San Isidro de Madrid", Sefarad (VIII): 97-116.

Trigueras Gordillo, G. y Gómez García, M. ${ }^{\text {a }}$ N. (2000). Los manuales de Textos en la Enseñanza Secundaria (1812-1990) Sevilla, Kronos.

Tusquets, J. (1975): "'Existenciar' la enseñanza media", Revista de Educación (238): 84-91. 
Úbeda de los Cobos, A. (1988): Pintura, mentalidad e ideología en la Real Academia de Bellas Artes de San Fernando, 1741-1800, Madrid, UCM.

Utande Igualada, M. (1964): Planes de estudio de enseñanza media, Madrid, Ministerio de Educación Nacional.

- (1975): "Treinta años de enseñanza media.1938-1968", Revista de Educación (240): 7-41.

- (1982): "Un siglo y medio de segunda enseñanza. 1820-1970", Revista de Educación (271): 7-41.
Valle López, A. (1990): La Universidad Complutense y su distrito en el primer decenio de la Restauración borbónica (1875-1885), dos volúmenes, Madrid, Consejo de Universidades.

Viñao Frago, A. (1975): "Educación secundaria y transformaciones socioeconómicas", Revista de Educación (238): p. 5-14.

- (1982): Política y educación en los orígenes de la España contemporánea. Examen especial de las relaciones en la enseñanza secundaria, Madrid, Siglo XXI.
- (1992): "Del bachillerato a la enseñanza secundaria (1938-1990)", Revista Española de Pedagogía (192): 321-340.

- (2000): "Un modelo de reforma educativa: los institutos-escuela (19181936)", en Boletín de la Institución Libre de Enseñanza. II Época (39): 63-88.

- (2004): Escuela para todos. Educación y modernidad en la España del siglo XX, Madrid, Marcial Pons, pp. 139-143. 